\title{
PAISAGENS INSULARES DO CEARÁ: NÚMERO, DISTRIBUIÇÃO GEOGRÁFICA E CARACTERIZAÇÃO ESTRUTURAL NAS BACIAS DO ALTO JAGUARIBE, DO BANABUIÚ E DO SALGADO
}

\author{
ARNÓBIO DE MENDONÇA BARRETO CAVALCANTE ${ }^{1}$
}

FRANCISCO FELICIANO DO RÊGO FILHO

JOÃO SILVIO DANTAS DE MORAES

Universidade Estadual do Ceará

\section{Introdução}

Nas últimas décadas, em diferentes partes do mundo, a crescente demanda humana por mais água, alimento, espaço e energia tem levado paisagens naturais a serem reduzidas, modificadas ou substituídas por cidades, campos agrícolas, pastagens e mineração. No Nordeste do Brasil não foi diferente. Por ser uma região predominantemente semiárida, vários açudes lá foram construídos. Desse modo, dada a introdução de massasd'água em terras secas, os açudes remodelaram de forma definitiva a paisagem semiárida brasileira. Aqui, paisagem é entendida, segundo Green, Simmons e Woltjer (1996), como uma configuração particular da topografia, cobertura vegetal, uso e ocupação da terra que delimita processos e atividades naturais e culturais.

Açude (árabe, as-sudd) significa o conjunto constituído por barragem ou barramento de um curso-d'água e o respectivo reservatório ou lago formado (www.srh.ce.gov.br). Existem em diferentes tamanhos. Os

\footnotetext{
${ }^{1}$ arnobio@secrel.com.br
} 
menores secam em anos de estiagem, porém outros permanecem com água mesmo nas secas mais avassaladoras. Esses últimos são açudes perenes e têm proporcionado valiosa contribuição ao homem. Primariamente, disponibilizam água para o abastecimento humano. Ademais, atendem à agricultura, à pecuária, à indústria, à geração de energia elétrica, controle de enchentes, pesca, lazer etc. Contudo, também acarretam prejuízos, e, contextualizado na ecologia de paisagem, emerge o processo denominado fragmentação da paisagem.

A fragmentação da paisagem encerra de forma simplista um processo de ruptura na continuidade da paisagem (LORD e NORTON, 1990). Evidencia-se quando uma grande área intacta é dividida em várias áreas intactas menores. A literatura científica registra inúmeras ocorrências desse processo como resultado de atividades naturais e humanas. Em sua quase totalidade, a fragmentação provoca mudanças drásticas nas paisagens e na biodiversidade onde opera.

Nas paisagens é citado que são perdidas, reduzidas, modificadas e outras criadas. Para esse último caso, são emblemáticas as paisagens insulares ou ilhas artificiais nos açudes do semiárido brasileiro (CAVALCANTE, 2008). A conexão entre fragmentação da paisagem e açude ocorre quando o rio represado e seu subsequente lago formado passam a abrigar pelo menos uma paisagem insular.

As paisagens insulares são antigos altos topográficos relativamente pequenos em área, aflorados no espelho-d'água dos açudes. Elas se configuram como áreas remanescentes de uma paisagem natural não mais existente, perdida por causa de uma drástica intervenção humana na natureza, a açudagem. Esses novos espaços antropogênicos se encontram dispersos por vários açudes do semiárido brasileiro. Felizmente, essas recentes paisagens (a mais antiga tem aproximadamente 100 anos) estão sendo paulatinamente vistas como áreas singulares e atrativas para o desenvolvimento de pesquisas em ecologia da paisagem e biogeografia, entre outras ciências.

As razões para o crescente interesse dos cientistas pelas paisagens insulares lacustres se explicam por sua multiplicidade, que assegura as repetições necessárias para testar hipóteses, pelas variadas características estruturais (tamanho, forma, relevo e isolamento), pela documentação oficial disponível (mapas, aerofotos etc.) e, sobretudo, por abrigar humanos, plantas e animais (selvagens e domésticos), coexistindo em espaços reduzidos e isolados, característica oportuna para melhor 
compreender como a vida selvagem interage e persiste nessas condições limitantes.

O estado do Ceará, que pertence à região Nordeste, pode oferecer grande contribuição, pois detém inúmeras ilhas, dada a construção em seu território de vários açudes públicos de porte (CAVALCANTE, 2008). O primeiro construído foi o de Cedro, no município de Quixadá, em 1906, também o primeiro do Brasil. O açude Castanhão, no município de Alto Santo, foi o último de porte construído, em 2003, maior de todos, com um espelho-d'água de $325 \mathrm{~km}^{2}$ (baía de Guanabara: $380 \mathrm{~km}^{2}$ ). Porém, pouco se sabe sobre essas paisagens insulares, e dessa forma tornou-se pertinente perguntar: quantas existem? Onde ocorrem? Como se apresentam estruturalmente?

A paisagem insular lacustre, como qualquer outra unidade da ciência pode ser estudada em sua estrutura, seu funcionamento e sua dinâmica. Este trabalho se dedica à estrutura, tendo como objetivo geral contribuir para o Projeto Inventário das Ilhas Continentais do Ceará e Conservação da Caatinga - P2I4C (CNPq/Uece), ao trabalhar três das 11 bacias hidrográficas previstas. Os objetivos específicos são os seguintes: determinar o número e a distribuição geográfica insular nas bacias do Alto Jaguaribe, do Banabuiú e do Salgado; caracterizar cada ilha, estruturalmente, quanto ao tamanho, à forma e ao isolamento.

\section{Material e métodos}

\section{Área de estudo}

A área de estudo do trabalho compreendeu três das 11 bacias hidrográficas do Ceará: bacia do Alto Jaguaribe, com 18 açudes; do Banabuiú, com 17; do Salgado, com 13 (figura 1). A seleção das bacias seguiu a ordem estabelecida no P2I4C, do qual este trabalho é um subprojeto. 


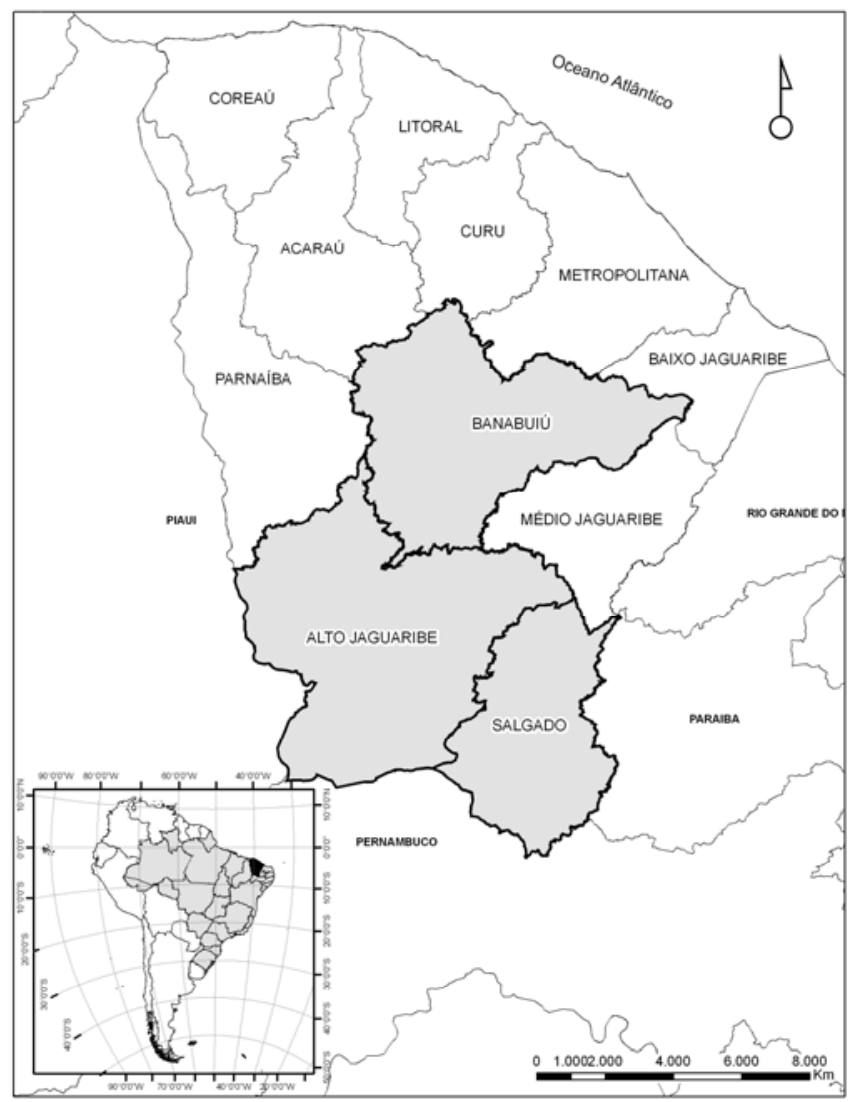

Figura 1 - Mapa das bacias hidrográficas do Ceará destacando as bacias investigadas.

Seleção dos açudes

Para cada bacia hidrográfica somente os açudes gerenciados pela Companhia de Gestão dos Recursos Hídricos (Cogerh) foram considerados, por serem açudes públicos, dotados de dados e informações (aerofotografias, histórico de construção, mapas etc.), e, sobretudo, de porte, o que supostamente os credenciam como reservatórios perenes.

Os açudes foram submetidos, mediante uso de seus mosaicos de aerofotografias verticais coloridas na escala de 1:10.000 de 2004, a uma interpretação aerofotográfica para identificar aqueles detentores de pelo menos uma ilha. Portanto, a seleção dos açudes em cada bacia hidrográfica 
foi encerrada quando alcançado o conjunto dos açudes gerenciados pela Cogerh e detentores de pelo menos uma ilha (figura 2).

Figura 2 - Mosaico aerofotográfico do açude Banabuiú (bacia do Banabuiú) dotado de ilhas, em 11/2004. Fonte: COGERH.

Interpretação aerofotográfica insular

Para aceitar uma dada área isolada identificada no mosaico aerofotográfico (imagem) do açude como ilha, aqui ilha foi entendida como uma área de terra firme circundada de água resultante do afloramento, no espelho-d'água, de altos topográficos pertencentes à bacia hidráulica. Dessa maneira, não se consideraram ilha as seguintes áreas isoladas: afloramentos rochosos, bancos de areia, ilhas fluviais e manchas de vegetação hidrófila e higrófila. A primeira exclusão se justifica devido ao fato de a rocha aflorada não possuir solo constituído (terra) e, muitas vezes, mostrar-se em dimensões reduzidas como pontas de pedras. $\mathrm{O}$ banco de areia, por sua vez, é uma área de solo desagregado formado por ação fluvial e efêmero. A exclusão de área insular decorrente da bifurcação e da 
confluência do rio afluente se justifica devido ao fato de a área estar fora dos limites da bacia hidráulica do açude. Por último, manchas isoladas de vegetação hidrófila (plantas aquáticas) e higrófila (plantas ribeirinhas) não foram consideradas ilhas por não apresentarem terra firme aflorada. Nesse caso, dado não ser tarefa fácil distinguir na imagem aglomerados de Eichornia crassipes (aguapé) ou Juncus sp. (junco), bem como copas de árvores como Mangifera indica (mangueira) ou Licania rigida (oiticica), de ilhas verdadeiras, num primeiro momento a área que levantou dúvida foi considerada ilha para, posteriormente, ser ou não descartada com a visita in loco.

\section{Problema emergente}

Um problema metodológico emerge quando se trabalha com ilhas artificiais lacustres em região semiárida. O problema decorre de as ilhas apresentarem variações estruturais em curto período. Essas variações estão atreladas ao nível da água em vigor nos açudes, que, por sua vez, dependem de chuvas irregulares no tempo-espaço que tipificam a região onde o trabalho foi realizado. Desse modo, uma ampla flutuação anual no nível da água dos açudes ocorre, fazendo com que as características mais conspícuas das ilhas (tamanho, forma, isolamento e número) sofram alterações consideráveis, há curto prazo. Por conseguinte, uma leitura estrutural realizada hoje, decerto, estaria distorcida dias depois.

Diante desse fato inevitável, foi tomada a seguinte posição metodológica: a obtenção das características estruturais das ilhas partiria, tão somente, da leitura de uma única imagem do açude, não importando o nível da água em vigor. Portanto, este trabalho procedeu a uma única leitura da paisagem insular alvo, não estando preocupado com sua dinâmica estrutural. A imagem utilizada foi considerada soberana, mesmo sabendo que outra estrutura poderia estar presente na visita in loco. As visitas, por sua vez, foram realizadas quando necessárias, em conformidade com as datas de tomadas das aerofotografias, uma tentativa de buscar maior similitude das imagens com o que se visualizava no campo.

Delimitação da bacia hidráulica e das ilhas

Em regra, a delimitação da bacia hidráulica e das ilhas a partir do mosaico aerofotográfico foi baseada, simplesmente, no traçado da linha de contorno do espelho-d'água. Para algumas partes do espelho-d'água, no 
entanto, tal procedimento não foi fielmente aplicado. Na cabeceira da bacia hidráulica (área de contato do rio com o lago), no ponto em que duas linha de contorno do espelho-d'água assumem uma disposição paralela ou a forma de um rio, elas foram conectadas em ângulo reto com suas trajetórias originais, de modo que o segmento do espelho-d'água a montante (rio) foi descartado. Para as bordas da bacia hidráulica e das ilhas quando revestidas de vegetação higrófila ou hidrófila, a delimitação considerou a vegetação; ou seja, o traçado superpõe-se à vegetação.

Tratamento das imagens e geração de mapas categóricos

Os mosaicos aerofotográficos em meio digital dos açudes selecionados receberam os seguintes tratamentos:

1) Foi extraída da imagem a bacia hidráulica do açude, aqui composta do espelho-d'água e ilha(s). O recorte (grosseiro) diminuiu o tamanho do arquivo de imagem, tornando seu processamento mais rápido. O recorte foi operacionalizado pelo software Arcview GIS 3.2.

2) Ajustou-se o histograma do recorte para permitir melhor visualização e interpretação da bacia hidráulica. A interpretação se refere à localização da ilha na bacia.

3) O terceiro tratamento foi a vetorização da bacia hidráulica e das ilhas identificadas. A vetorização foi processada com o uso do software Autodesk Map 2000i. O arquivo gerado foi do tipo ShapeFile (.shp), formato aceito pelo programa Fragstats. Assim, gerou-se um mapa categórico de legenda simples, contendo espelho-d'água e ilha.

Caracterização estrutural da paisagem

Aplicou-se em cada ShapeFile (.shp) o software Fragstats for Arcview (V. 1.0). O Fragstats é um programa que analisa padrões espaciais, usado para quantificar a estrutura da paisagem (MCGARIGAL e MARKS, 1995). O programa calcula várias métricas (índices de paisagem) que estão agrupadas em níveis: 1) Fragmento individual; 2) Classe (conjunto de fragmentos do mesmo tipo); 3) Paisagem (paisagem inteira). Desse modo, três arquivos de saída foram gerados em formato dBase IV (.dbf) por açude: fragmento (Patch), classe (Class) e paisagem (Land). 
Foi criado um banco de dados, cujas métricas se apresentam por bacia hidrográfica, em ordem alfabética dos açudes e por nível. O banco de dados subsidiou a análise e a interpretação das estruturas das paisagens estudadas. Acentua-se que os fragmentos são as ilhas, um conjunto de ilhas constitui uma classe, a paisagem inteira sendo a bacia hidráulica com as ilhas inseridas. Utilizaram-se do banco de dados somente das métricas de área, perímetro, índice de forma, dimensão fractal, distância mais próxima ao continente e número de ilhas, métricas relacionadas às características: tamanho, forma, isolamento e número. O significado ecológico, a descrição narrativa, a fórmula matemática, o nível de uso recomendado, a unidade e a faixa de variação dessas métricas podem ser obtidos em McGarigal e Marks (1995) e em Metzger (2003).

\section{Resultados e discussão}

Paisagens insulares: número e distribuição

Foram analisados 48 açudes públicos, dos quais 18, 17 e 13 deles pertencem às bacias do Alto Jaguaribe, do Banabuiú e do Salgado, respectivamente (www.srh.ce.gov.br). Para cada açude detentor de pelo menos uma ilha foi gerado um mapa, a partir do qual se conheceram o número, a distribuição e a localização geográfica das ilhas. Apresentaram pelo menos uma ilha 12 açudes da bacia do Alto Jaguaribe $(66,7 \%), 11$ da bacia do Banabuiú $(64,7 \%)$ e 9 da bacia do Salgado $(69,2 \%)$, totalizando nas três bacias hidrográficas 32 açudes (ou 66,7\% dos açudes investigados). O número total de ilhas levantadas nas três bacias foi 356 : 224 na bacia do Alto Jaguaribe, 87 na do Banabuiú e 45 na do Salgado (tabela 1).

A partir desse levantamento e trabalhando cada bacia hidrográfica em separado, procurou-se detectar fatores intrínsecos que justificassem a maior ou menor presença de ilhas nos açudes. Assim, inicialmente, confrontou-se o número de ilhas com a área dos espelhos-d'água dos reservatórios (tabela 2). 


\begin{tabular}{|c|c|c|c|c|c|c|c|}
\hline \multicolumn{2}{|c|}{$\begin{array}{c}\text { BACIA DO } \\
\text { ALTO JAGUARIBE }\end{array}$} & \multicolumn{2}{|c|}{$\begin{array}{l}\text { BACIA DO } \\
\text { BANABUIÚ }\end{array}$} & \multicolumn{2}{|c|}{$\begin{array}{l}\text { BACIA DO } \\
\text { SALGADO }\end{array}$} & \multicolumn{2}{|c|}{ TOTAL } \\
\hline Açudes & $\begin{array}{l}\mathrm{N}^{\mathrm{o}} \mathrm{de} \\
\text { ilha(s) }\end{array}$ & Açudes & $\begin{array}{l}\mathrm{N}^{\mathrm{o}} \mathrm{de} \\
\text { ilha(s) }\end{array}$ & Açudes & $\begin{array}{l}\mathrm{N}^{\mathrm{o}} \mathrm{de} \\
\text { ilha(s) }\end{array}$ & Açudes & Ilhas \\
\hline Benguê & 02 & Banabuiú & 27 & Atalho & 09 & & \\
\hline Canoas & 01 & Cipoada & 02 & Cachoeira & 07 & & \\
\hline Favelas & 01 & Fogareiro & 27 & Lima Campos & 02 & & \\
\hline $\begin{array}{l}\text { Forquilha } \\
\text { II }\end{array}$ & 02 & Patu & 03 & $\begin{array}{l}\text { Manoel } \\
\text { Balbino }\end{array}$ & 01 & & \\
\hline Muquém & 11 & $\begin{array}{l}\text { Pedras } \\
\text { Brancas }\end{array}$ & 12 & Quixabinha & 02 & & \\
\hline Orós & 168 & Poço do Barro & 04 & Rosário & 15 & & \\
\hline Parambu & 02 & $\begin{array}{l}\text { Quixeramobi } \\
\text { m }\end{array}$ & 01 & Tatajuba & 01 & & \\
\hline $\begin{array}{l}\text { Poço da } \\
\text { Pedra }\end{array}$ & 01 & Serafim Dias & 04 & $\begin{array}{l}\text { Thomás } \\
\text { Osterne }\end{array}$ & 01 & & \\
\hline Quincoé & 05 & São José I & 01 & Ubaldinho & 07 & & \\
\hline $\begin{array}{l}\text { Rivaldo de } \\
\text { Carvalho }\end{array}$ & 03 & São José II & 01 & & & & \\
\hline Trussu & 26 & Vieirão & 05 & & & & \\
\hline $\begin{array}{l}\text { Várzea do } \\
\text { Boi }\end{array}$ & 02 & & & & & & \\
\hline 12 & 224 & 11 & 87 & 09 & 45 & 32 & 356 \\
\hline
\end{tabular}

Tabela 1 - Açudes com seus respectivos números de ilhas e distribuídos por bacia hidrográfica.

Começando pela bacia do Salgado, cuja distribuição das 45 ilhas dos açudes revelou desuniformidade acentuada, isto é, açudes com uma ou duas ilhas, e outros com sete, nove e até 15 ilhas. Constatou-se nessa bacia que a maior ou menor área do espelho-d'água do açude não estabelece relação direta com o número de ilhas por ele abrigado. Os açudes com maior área de espelho-d'água não apresentam obrigatoriamente abundância de ilhas, e o mesmo é válido para os açudes menores, ou seja, raridade insular. Exemplo disso foi o açude Rosário, segundo menor em área $\mathbf{7 6 , 0}$ ha), detendo o maior número de ilhas na bacia: 15 ao todo. Já o açude Lima Campos, maior reservatório entre todos $(917,9$ ha), abrigava tão somente duas ilhas. 


\begin{tabular}{|c|c|c|c|c|c|c|c|c|}
\hline \multicolumn{3}{|c|}{$\begin{array}{c}\text { BACIA DO } \\
\text { ALTO JAGUARIBE }\end{array}$} & \multicolumn{3}{|c|}{$\begin{array}{c}\text { BACIA DO } \\
\text { BANABUIÚ } \\
\end{array}$} & \multicolumn{3}{|c|}{$\begin{array}{l}\text { BACIA DO } \\
\text { SALGADO }\end{array}$} \\
\hline Açudes & $\begin{array}{c}\text { Área } \\
\text { (ha) }\end{array}$ & $\begin{array}{l}\mathrm{N}^{0} \mathrm{de} \\
\text { ilha(s) }\end{array}$ & Açudes & $\begin{array}{c}\text { Área } \\
\text { (ha) }\end{array}$ & $\begin{array}{l}\mathrm{N}^{\mathrm{o}} \mathrm{de} \\
\text { ilha(s) }\end{array}$ & Açudes & $\begin{array}{l}\text { Área } \\
\text { (ha) }\end{array}$ & $\begin{array}{l}\mathrm{N}^{0} \text { de } \\
\text { ilha(s) } \\
\end{array}$ \\
\hline $\begin{array}{l}\text { Forquilha } \\
\text { II }\end{array}$ & 28,8 & 2 & São José I & 104,5 & 1 & Quixabinha & 57,4 & 2 \\
\hline $\begin{array}{l}\text { Poço da } \\
\text { Pedra }\end{array}$ & 46,0 & 1 & $\begin{array}{l}\text { Quixeram } \\
\text { obim }\end{array}$ & 313,5 & 1 & Rosário & 76,0 & 15 \\
\hline Parambu & 122,4 & 2 & Cipoada & 349,5 & 2 & Tatajuba & 76,0 & 1 \\
\hline Quincoé & 143,2 & 5 & $\begin{array}{l}\text { São José } \\
\text { II }\end{array}$ & 410,7 & 1 & M. Balbino & 117,7 & 1 \\
\hline Canoas & 217,1 & 1 & Vieirão & 442,9 & 5 & T. Osterne & 221,4 & 1 \\
\hline $\begin{array}{c}\text { R. de } \\
\text { Carvalho }\end{array}$ & 248,5 & 3 & $\begin{array}{l}\text { Poço do } \\
\text { Barro }\end{array}$ & 452,5 & 4 & Atalho & 272,6 & 9 \\
\hline Favelas & 354,9 & 1 & Patu & 526,5 & 3 & Cachoeira & 319,6 & 7 \\
\hline Benguê & 919,1 & 2 & $\begin{array}{l}\text { Serafim } \\
\text { Dias }\end{array}$ & 611,0 & 4 & Ubaldinho & 372,0 & 7 \\
\hline Muquém & 934,8 & 11 & $\begin{array}{l}\text { Pedras } \\
\text { Brancas }\end{array}$ & $1.360,4$ & 12 & L. Campos & 917,9 & 2 \\
\hline Trussu & $2.176,2$ & 26 & Fogareiro & $2.732,4$ & 27 & & & \\
\hline Orós & $5.354,4$ & 168 & Banabuiú & $5.755,5$ & 27 & & & \\
\hline
\end{tabular}

Várzea do $\quad 6.443,2 \quad 2$

Boi

Tabela 2 - Açudes em ordem crescente de área e seus respectivos números de ilhas.

Diante disso, a ideia de açudes maiores tenderem a abrigar maior número de ilhas não constitui um padrão, conforme sugerido por Cavalcante (2008) quando trabalhou com as bacias Metropolitanas, Curu e Baixo Jaguaribe do mesmo estado. Desse modo, buscou-se outro fator, além do tamanho da área do espelho-d'água, que estivesse determinando de forma mais decisiva esse aspecto. Focou-se no relevo, e para tal foram observados os posicionamentos geográficos dos açudes em carta hipsométrica do Ceará.

Ao verificar o modelo plástico do relevo da bacia do Salgado (RÊGO FILHO, 2008), caracterizada por apresentar relevo nitidamente dissecado, logo se percebeu a tendência de quanto mais dissecado o relevo onde ocorria um dado açude, maior a presença de ilhas afloradas em seu espelho-d'água. Além disso, ao comparar a bacia em questão à Metropolitana (CAVALCANTE, 2008), evidenciou-se a importância do 
relevo na quantificação insular. A bacia Metropolitana, posicionada próxima ao litoral em relevo suave a ondulado, detentora de oito açudes com 35 ilhas e um somatório de espelhos-d'água duas vezes e meia superior ao da bacia do Salgado, embora com um número próximo de açudes, revelou dez ilhas a menos.

A bacia do Alto Jaguaribe, por sua vez, cuja distribuição das 224 ilhas nos açudes foi bastante irregular, a exemplo do que aconteceu na bacia do Salgado e de forma até mais pronunciada, corroborou a inexistência de um padrão alicerçado unicamente em açudes maiores, mais ilhas abrigadas. Aqui, é emblemático o açude de maior área na bacia, Várzea do Boi, detentor de apenas duas ilhas. Contudo, os açudes Orós e Trussu, segundo e terceiro em área, respectivamente, destacaram que o tamanho do espelho-d'água continua sendo ainda um importante fator ou forte influenciador do número de ilhas. $\mathrm{O}$ mesmo se verificou para os menores açudes da bacia, Forquilha II (figura 3) e Poço da Pedra (tabela 2).

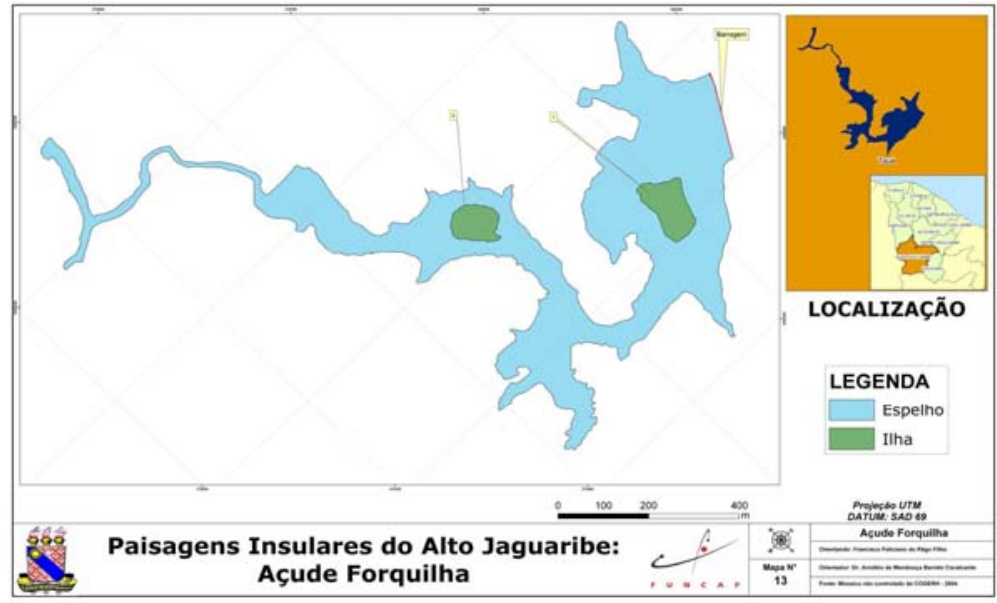

Figura 3 - Mapa do açude Forquilha II, bacia do Alto Jaguaribe.

A bacia do Banabuiú, a última entre as bacias hidrográficas estudadas, também fortaleceu o efeito do tamanho do espelho-d'água como fator importante na determinação do número de ilhas. Os dois maiores açudes da bacia, Fogareiro e Banabuiú, apresentaram o maior número de ilhas: 27 cada. Da mesma forma, os dois menores, São José I e Quixeramobim, mostraram apenas uma ilha cada (tabela 2). Essa bacia foi a que revelou, mediante uso de seu modelo plástico de relevo, açudes localizados em áreas menos dissecadas. Por essa razão, o fator tamanho do 
espelho-d'água foi importante na determinação do número de ilhas, tal como aconteceu com a bacia Metropolitana.

Portanto, considerando conjuntamente as três bacias hidrográficas, pode-se conjecturar que os fatores que participam mais efetivamente na quantidade e na distribuição insular nos açudes são a área do espelhod'água e o relevo, e que esses fatores devem ser considerados conjuntamente. Assim, quanto maior for a área do espelho-d'água no açude e mais dissecado o relevo onde o mesmo se localiza, maiores serão as possibilidades do açude de abrigar maior número de ilhas. Ademais, nas bacias posicionadas mais ao sul do estado onde o relevo se revela mais dissecado, o dito fator exerce maior influência sobre os aspectos supra, ao passo que, para as bacias mais próximas da linha costeira onde o relevo tende a suavizar, ganha maior importância o fator área do espelho-d'água.

\section{Tamanhos das ilhas}

A partir dos arquivos Path gerados pelo Fragstat, balizaram-se os tamanhos ou áreas das ilhas levantadas entre $0,01\left(100 \mathrm{~m}^{2}\right)$ e 78,64 ha, extremos inferior e superior respectivamente. Para o extremo inferior, coube a ilha de número 13 (açude Fogareiro, bacia do Banabuiú). Para o extremo oposto, a ilha de maior área ficou representada pela de número 2 (açude Benguê, bacia do Alto Jaguaribe). Entre esses extremos as áreas das ilhas variaram amplamente.

A tabela 3 apresenta as ilhas inventariadas distribuídas por classes de área. A que mais acolheu ilhas foi a classe até 0,5 ha, com 182 ilhas (51,1\% do total). Em seguida, apareceu a classe acima de 1,0 ha a 2,0 ha, com 59 ilhas $(16,6 \%)$; que suplantou a classe acima de 0,5 ha a 1,0 ha, imediatamente anterior, com 54 ilhas $(15,1 \%)$. A que menos abrigou ilhas foi a classe acima de 4,0 ha até igual a 8,0 ha, com 11 ilhas $(3,1 \%)$. Essa classe foi quantitativamente inferior à última, acima de 8,0 ha, que recebeu 21 ilhas (5,9\%). Percebeu-se, com isso, que a redução numérica gradual insular à medida que se avança nas classes de área, da menor para a maior, foi interrompida em duas ocasiões. 


\begin{tabular}{cccccccc}
\hline & \multicolumn{2}{c}{$\begin{array}{c}\text { BACIA DO } \\
\text { ALTO }\end{array}$} & \multicolumn{2}{c}{$\begin{array}{c}\text { BACIA DO } \\
\text { BANABUIÚ }\end{array}$} & \multicolumn{2}{c}{$\begin{array}{c}\text { BACIA DO } \\
\text { SALGADO }\end{array}$} \\
\hline $\begin{array}{c}\text { JAGUARIBE } \\
\text { de área } \\
\text { (ha) }\end{array}$ & $\begin{array}{c}\text { Número } \\
\text { de ilhas }\end{array}$ & $\begin{array}{c}\% \text { do } \\
\text { total }\end{array}$ & $\begin{array}{c}\text { Número } \\
\text { de ilhas }\end{array}$ & $\begin{array}{c}\% \text { do } \\
\text { total }\end{array}$ & $\begin{array}{c}\text { Número } \\
\text { de ilhas }\end{array}$ & $\begin{array}{c}\% \text { do } \\
\text { total }\end{array}$ & $\begin{array}{c}\text { Total da } \\
\text { classe }\end{array}$ \\
\hline$\leq 0,5$ & 112 & 50,0 & 46 & 52,9 & 24 & 53,3 & 182 \\
$0,5-1,0$ & 37 & 16,5 & 11 & 12,6 & 06 & 13,3 & 54 \\
$1,0-2,0$ & 39 & 17,5 & 13 & 14,9 & 07 & 15,6 & 59 \\
$2,0-4,0$ & 13 & 5,8 & 09 & 10,3 & 07 & 15,6 & 29 \\
$4,0-8,0$ & 07 & 3,1 & 03 & 3,5 & 01 & 2,2 & 11 \\
$>8,0$ & 16 & 7,1 & 05 & 5,8 & -- & -- & 21 \\
\hline Total & 224 & 100,0 & 87 & 100,0 & 45 & 100, & 356 \\
& & & & & & 0 & \\
\hline
\end{tabular}

Tabela 3 - Número de ilhas por classes de área nas bacias Alto Jaguaribe, Banabuiú e Salgado.

Embora tenham aqui existido essas quebras de continuidade, de maneira geral permanece ainda a tendência de declínio na quantidade de ilhas quando se avança na grandeza das classes. Basta observar que as três primeiras classes de área abrigaram os maiores números de ilhas (259 ou $82,9 \%$ do total) e que as três últimas registraram os menores números (61 ou $17,1 \%$ ). Portanto, mantém-se a tendência de ilhas menores serem mais abundantes e ilhas cada vez maiores mais raras nos açudes, conforme detectada por Cavalcante (2008) nos açudes das bacias Metropolitana, Curu e Médio Jaguaribe.

Essa tendência já era esperada, haja vista que ilhas grandes ocupam espaços maiores nos açudes, que, por sua vez, deverão ser grandes o suficiente para abrigá-las e, simultaneamente, armazenar quantidade expressiva de água. Não faz sentido construir um açude de porte pequeno ou médio em cuja bacia hidráulica acomode uma enorme ilha em seu interior. Isso, certamente, repercute na capacidade de armazenamento hídrico do mesmo, ou seja, menos água armazenada. Portanto, como os açudes grandes em superfície, por exemplo, Várzea do Boi, Banabuiú e Orós, entre outros, se mostram em número reduzido, isso desfavoreceu o surgimento de ilhas maiores no levantamento.

Comparando as bacias conforme a tabela 3 , destacadamente a do Alto Jaguaribe foi a que mais apresentou conjuntos de numerosas ilhas por classes de área. Essa bacia deteve o conjunto mais numeroso de ilhas miúdas (áreas até 0,5 ha), com 112 ilhas (61,5\% das ilhas da classe). A 
bacia também abrigou o maior conjunto de ilhas pequenas $(0,5>$ ilha pequena $\leq 1,0 \mathrm{ha}$ ), com 37 ilhas $(68,5 \%)$, e os maiores conjuntos para ilha pequeno-média $(1,0>$ ilha pequeno-média $\leq 2,0 \mathrm{ha})$, médio-grande $(2,0>$ ilha médio-grande $\leq 4,0 \mathrm{ha})$, grande $(4,0>$ ilha grande $\leq 8,0 \mathrm{ha})$ e enorme $(>8,0 \mathrm{ha})$, respectivamente, com $39(66,1 \%), 13(44,8 \%), 7(63,6 \%)$ e 16 $(76,2 \%)$.

O responsável por essa superioridade na distribuição insular foi o açude Orós, que detém 168 ilhas, ou $75 \%$ do total de ilhas da bacia do Alto Jaguaribe, ou, ainda, $47,2 \%$ das ilhas das três bacias estudadas. Para dar uma ideia de sua grandeza, se esse açude fosse removido do levantamento a bacia do Alto Jaguaribe passaria a ter 56 ilhas, automaticamente caindo para segundo lugar entre as bacias investigadas e ficando pouco acima da bacia do Salgado, bacia com menor número de ilhas.

Portanto, dada a nítida supremacia numérica de ilhas para a totalidade das classes de tamanho frente às demais bacias envolvidas, a do Alto Jaguaribe, aqui representando suas ilhas, credencia-se como área promissora para desenvolver investigações no âmbito da biogeografia e da ecologia da paisagem. A quantidade insular lá disponível, com seus diferentes tamanhos, é condição atrativa para testar hipóteses.

A área de um fragmento (aqui de uma ilha artificial) é talvez o dado mais importante e útil na análise da estrutura de uma paisagem ecológica (MCGARIGAL e MARKS, 1995), além de ser a característica da paisagem mais facilmente reconhecida. Sua importância se evidencia no planejamento de uso da terra envolvendo projetos que criam reservas para a vida selvagem.

Teoricamente, áreas maiores suportam maior diversidade de espécies (MACARTHUR e WILSON, 1967). Numerosos trabalhos abordando a área do fragmento ou ilha de habitat sobre a biodiversidade estão disponíveis, como Saunders et al. (1987) e Metzger (1999). Assim, parece justificável conhecer o tamanho de cada ilha artificial na paisagem e tornar possível relacionar com parâmetros biológicos.

Formas das ilhas

As formas das ilhas foram estudadas por meio de dois índices de forma, cujos dados foram extraídos dos arquivos Patch gerados pelo Fragstat. Para o primeiro índice, Shape Index (Shapei), que se baseia no quociente perímetro/área e avalia a complexidade da forma de uma mancha 
comparando-a a uma forma circular - vetor de mesma área -, as formas das ilhas levantadas ficaram balizadas pelos valores 1,02 e 2,95 (adimensional), mais simples e mais complexa respectivamente.

O Shape atribui o valor 1 para a forma circular e aumenta, sem limites, à medida que a forma se torna mais irregular (MCGARIGAL e MARKS, 1995). Nessas condições, pode-se afirmar que todas as ilhas apresentaram forma não circular. A ilha cuja forma mais se aproximou da forma circular foi a de número 3 (açude Quincoé, bacia do Alto Jaguaribe), registrando Shapei 1,02. Já a ilha de forma mais complexa, com Shapei 2,95, foi a de número 26 (açude Trussu, bacia do Alto Jaguaribe). Observou-se que a forma predominante das ilhas para todos os açudes foi aquela tendendo ao arredondamento, com numerosos Shapei obtidos mais próximos a 1. Poucas ilhas, precisamente 17 de um total de 356, apresentaram forma mais complexa, com os Shapei registrando valores superiores a 2 .

O segundo índice utilizado, a Dimensão Fractal (Fract), toma valores entre 1 e 2, considerando que valores próximos a 1 indicam formas geométricas simples (círculo) e valores próximos a 2 formas mais complexas (op. cit.). Desse modo, o Fract indicou que a ilha cuja forma mais se aproximou da forma circular foi a de número 2 (açude Benguê, bacia do Alto Jaguaribe), com Fract igual a 1,22. Por sua vez, a que registrou a forma mais complexa, Fract 1,54, foi a ilha 6 (açude Ubaldinho, bacia do Salgado). O Fract também indicou que nenhuma ilha apresentou a circularidade perfeita e que existiu, de modo geral, clara predominância da forma tendendo ao arredondamento, em conformidade com o índice anterior.

Quando os valores dos dois índices foram confrontados, uma constatação, que requer melhor entendimento e que está fora dos propósitos deste trabalho, emergiu referente ao porquê da não equivalência ou "sintonia" entre os dois índices ao tomar uma mesma ilha. Por exemplo, a ilha de maior Shapei não correspondeu à ilha de maior Fract, como supostamente seria esperado. $\mathrm{O}$ mesmo se repetiu em relação às ilhas de menor Shapei e Fract. Além disso, valores de Fract até revelaram discrepância, em várias situações, quando se tomaram ilhas distintas com iguais valores de Shapei. Essa não correspondência foi também percebida por Cavalcante (2008).

Os índices supracitados são de aplicação exclusiva para o nível fragmento ou mancha, neste trabalho a ilha. Quando as ilhas são tomadas em conjunto, formam uma classe (classe-ilha). Assim, as bacias do Alto 
Jaguaribe, do Banabuiú e do Salgado tiveram, também, suas classes-ilha mensuradas por meio do índice de forma médio (MSI), calculado para o nível classe.

O MSI assume o valor 1 quando todos os fragmentos da classe apresentam a forma circular e aumenta, sem limites, à medida que suas formas se tornam mais irregulares (MCGARIGAL e MARKS, 1995). Dessa maneira, ao tomar os dados MSI dos arquivos Class gerados pelo Fragstat, construiu-se a tabela 4. Assim, foi possível calcular a média dos MSI das bacias, obtendo-se os valores 1,31, 1,28 e 1,29 para as bacias do Alto Jaguaribe, do Banabuiú e do Salgado, respectivamente. Portanto, o conjunto insular de forma mais irregular pode ser encontrado na bacia do Alto Jaguaribe, e o conjunto com ilhas que tendem mais ao arredondamento, na do Banabuiú. O MSI maior atribuído à bacia do Alto Jaguaribe foi puxado pelos MSI dos açudes Várzea do Boi $(1,66)$, Poço da Pedra $(1,64)$ e Trussu $(1,56)$, enquadrados entre os cinco maiores MSI calculados.

\begin{tabular}{|c|c|c|c|c|c|}
\hline \multicolumn{2}{|c|}{$\begin{array}{c}\text { BACIA DO } \\
\text { ALTO JAGUARIBE }\end{array}$} & \multicolumn{2}{|c|}{$\begin{array}{l}\text { BACIA DO } \\
\text { BANABUIÚ }\end{array}$} & \multicolumn{2}{|c|}{$\begin{array}{l}\text { BACIA DO } \\
\text { SALGADO }\end{array}$} \\
\hline Açudes & MSI & Açudes & MSI & Açudes & MSI \\
\hline Benguê & 1,15 & Banabuiú & 1,33 & Atalho & 1,12 \\
\hline Canoas & 1,06 & Cipoada & 1,52 & Cachoeira & 1,25 \\
\hline Favelas & 1,15 & Fogareiro & 1,30 & Lima Campos & 1,70 \\
\hline Forquilha II & 1,17 & Patu & 1,49 & Manoel Balbino & 1,12 \\
\hline Muquém & 1,45 & Pedras Brancas & 1,22 & Quixabinha & 1,14 \\
\hline Orós & 1,35 & Poço do Barro & 1,19 & Rosário & 1,36 \\
\hline Parambu & 1,22 & Quixeramobim & 1,21 & Tatajuba & 1,10 \\
\hline Poço da Pedra & 1,64 & Serafim Dias & 1,36 & Thomás Osterne & 1,29 \\
\hline Quincoé & 1,10 & São José I & 1,18 & Ubaldinho & 1,58 \\
\hline $\begin{array}{l}\text { Rivaldo de } \\
\text { Carvalho }\end{array}$ & 1,25 & São José II & 1,07 & & \\
\hline Trussu & 1,56 & Vieirão & 1,22 & & \\
\hline Várzea do Boi & 1,66 & & & & \\
\hline MSI bacia & 1,31 & & 1,28 & & 1,29 \\
\hline
\end{tabular}

Tabela 4 - Índices de Forma Médios (MSI) para classe-ilha por açude e bacia hidrográfica. 
A característica estrutural Forma da ilha apresenta grande valor biogeográfico e ecológico, razão pela qual aqui foi calculado. No aspecto biogeográfico, dependendo da combinação de seu tamanho com a forma, uma ilha pode possuir borda e área de interior ou só borda. A ilha ao ser constituída de dois ambientes distintos (borda e ambiente interior), naturalmente aflora uma distribuição de espécies particular, atrativa para estudos biogeográficos.

O valor ecológico, por sua vez, está atrelado ao chamado Efeito de Borda. O Efeito de Borda consiste nas condições de reduzida diversidade de espécies com elevada abundância de indivíduos, maior exposição às perturbações externas e maior produtividade biológica verificadas nas bordas de fragmentos, apesar de esses efeitos nem sempre se aplicarem a todas as bordas (METZGER, 2003). Assim, quanto mais irregular for a forma de um fragmento, mais borda apresentará, exacerbando sua ação. Simplesmente, o Efeito de Borda seria uma decadência de espécies e interações ecológicas verificadas nas bordas de fragmentos.

Nas paisagens insulares ou ilhas artificiais aqui estudadas, curiosamente, um efeito de borda com características contrárias parece estar ocorrendo no aspecto riqueza e abundância de espécies. $\mathrm{O}$ empirismo sugere progresso e não decadência. Sutis evidências, como uma maior riqueza de espécies estabelecidas nas bordas das ilhas, sinalizam isso, sendo a água o possível fator primário responsável por essa inversão, uma vez que passou de escassa e limitante, a abundante e de fácil alcance.

Ainda na perspectiva ecológica, é sabido que resultados advindos somente da aplicação de índices ou métricas da paisagem não constituem, num primeiro momento, informações conservacionistas de imediata aplicação. A característica Forma só alcança sua plenitude em termos de contribuição para conservação ecológica quando cruzada com informações biológicas, biogeográficas e/ou ecológicas. No entanto, mesmo sem o devido cruzamento (não se constituiu objeto de investigação deste trabalho) os resultados aqui apresentados para as Formas das ilhas são de grande valor descritivo e suporte imprescindível ao cruzamento com dados biogeoecológicos.

Isolamento da ilhas

As medidas de distância da borda da ilha ao ponto continental mais próximo, constantes nos arquivos Next gerados pelo Arcview GIS 3.2, apontaram que as três ilhas mais remotas levantadas foram, em ordem 
decrescente, a de número 45 (açude Orós, bacia do Alto Jaguaribe), com $930 \mathrm{~m}$, a ilha 23 (açude Banabuiú, bacia do Banabuiú), com 916 m, e a ilha 24 (açude Trussu, bacia do Alto Jaguaribe), com $907 \mathrm{~m}$. Já as três mais próximas foram, em ordem crescente, a de número 6 (açude Muquém, bacia do Alto Jaguaribe), com $2 \mathrm{~m}$, a ilha 2 (açude Ubaldinho, bacia do Salgado), com $5 \mathrm{~m}$, e por último as ilhas 138, 161 e 165 (açude Orós, bacia do Alto Jaguaribe), com $6 \mathrm{~m}$ cada.

Outro resultado merecedor de menção diz respeito à localização geográfica preferencial de ilhas remotas nos açudes. Levando-se em conta seus mapas e em conformidade com os arquivos Next, estes sinalizaram maior presença dessas ilhas em áreas cercanas à barragem. Nessa parte do açude o espelho-d'água assume, normalmente, uma forma alargada que favorece o maior distanciamento das ilhas à borda. Desse modo, parece mais fácil encontrar ilhas remotas a partir da barragem do açude do que de qualquer outra parte sua. O mesmo foi detectado por Cavalcante (2008), sugerindo a possibilidade de um padrão.

Ainda, em conformidade com os arquivos Next e considerando o universo dos açudes, é possível sugerir açudes com pelo menos 11 ilhas (Muquém, Pedras Brancas, Rosário, Trussu, Fogareiro, Banabuiú e Orós) como potencialmente úteis ao desenvolvimento de pesquisas que envolvam efeitos do isolamento sobre a distribuição, a riqueza e a abundância de espécies, bem como processos ecológicos. A indicação de tais açudes se justifica por suas múltiplas, amplas e até repetidas medidas de distâncias apresentadas. Por exemplo, os açudes Banabuiú e Trussu oferecem aproximadamente 26 medidas de distâncias insulares cada, com grande amplitude entre o menor e o maior isolamento e até medidas de isolamento idênticas ou muito próximas. Portanto, disponibilizam-se nesses açudes variadas situações de isolamento e repetições, condições essenciais para firmar padrões. Isso fica mais enriquecido com a participação do açude Orós; porém, devido ao intenso uso-ocupação de suas ilhas, ocorreram notórias perdas de qualidade ecológica insular.

Tratando do número de ilhas por classes de isolamento, inicialmente, nenhum registro ocorreu de ilha cuja distância de sua borda ao ponto continental mais próximo estivesse acima de $1.000 \mathrm{~m}$, conforme já relatado. Agora, precisamente 7 ilhas (1,9\%) apresentaram distâncias iguais ou superiores a $800 \mathrm{~m}$. Numa porção maior (68 ilhas ou 19,1\% do total), o isolamento das ilhas se enquadrou entre $200 \mathrm{~m}$ e $800 \mathrm{~m}$ (classes 200-400 e 400-800 m). Porém, a maioria das ilhas (281 ou 78,9\%) obteve isolamento inferior a $200 \mathrm{~m}$ (tabela 5). A abundância de ilhas próximas à 
borda continental já era esperada, dada a dominância de açudes de pequeno e médio porte, situação semelhante encontrada por Cavalcante. (2008).

\begin{tabular}{cccc}
\hline $\begin{array}{c}\text { Classes de } \\
\text { isolamento } \\
(\mathrm{m})\end{array}$ & ALTO JAGUARIBE & BANABUIÚ & SALGADO \\
\hline$<25$ & Número de ilhas & Número de ilhas & Número de ilhas \\
$25-50$ & 44 & 10 & 10 \\
$50-100$ & 39 & 09 & 15 \\
$100-200$ & 49 & 26 & 09 \\
$200-400$ & 38 & 22 & 10 \\
$400-800$ & 36 & 12 & 01 \\
$\geq 800$ & 14 & 05 & -- \\
\hline Total & 04 & 03 & -- \\
\hline
\end{tabular}

Tabela 5 - Número de ilhas por classes de isolamento nas bacias Alto Jaguaribe, Banabuiú e Salgado.

Ao comparar as três bacias hidrográficas a partir da tabela 5 e atribuindo valores relativos às classes de isolamento, elaborou-se a figura 4. Não se constatou hegemonia de uma bacia sobre as demais, ou seja, todas ocuparam pelo menos duas vezes a liderança de classe. A bacia do Alto Jaguaribe liderou duas classes de isolamento: $200-400 \mathrm{~m}$ e $400-800$ m. A do Banabuiú foi primeiro lugar nas classes 50-100 m, 100-200 m e igual ou superior a $800 \mathrm{~m}$. A do Salgado foi líder nas classes até $25 \mathrm{~m}$ e $25-$ $50 \mathrm{~m}$. Esta última foi a única a não registrar ilhas em todas as classes de isolamento, com ausência insular nas duas últimas classes ou a partir da distância de $400 \mathrm{~m}$. Isso se justifica devido ao porte médio e formato longilíneo (maior comprimento e menor largura) dominantes em seus açudes, condições que desfavorecem a presença de ilhas mais isoladas.

Do ponto de vista da biogeografia e da ecologia, a distância de uma ilha a uma fonte (área continental ou não em perfeito estado de conservação) é uma valiosa informação. $\mathrm{O}$ isolamento pode afetar a qualidade biológica de uma ilha ao interferir no fluxo das espécies. Numerosos trabalhos na literatura científica demonstram que ilhas remotas abrigam menos espécies que ilhas de igual tamanho, porém localizadas próximas da fonte (MACARTHUR e WILSON, 1967; WHITTAKER e FERNÁNDEZ-PALACIOS, 2007). 


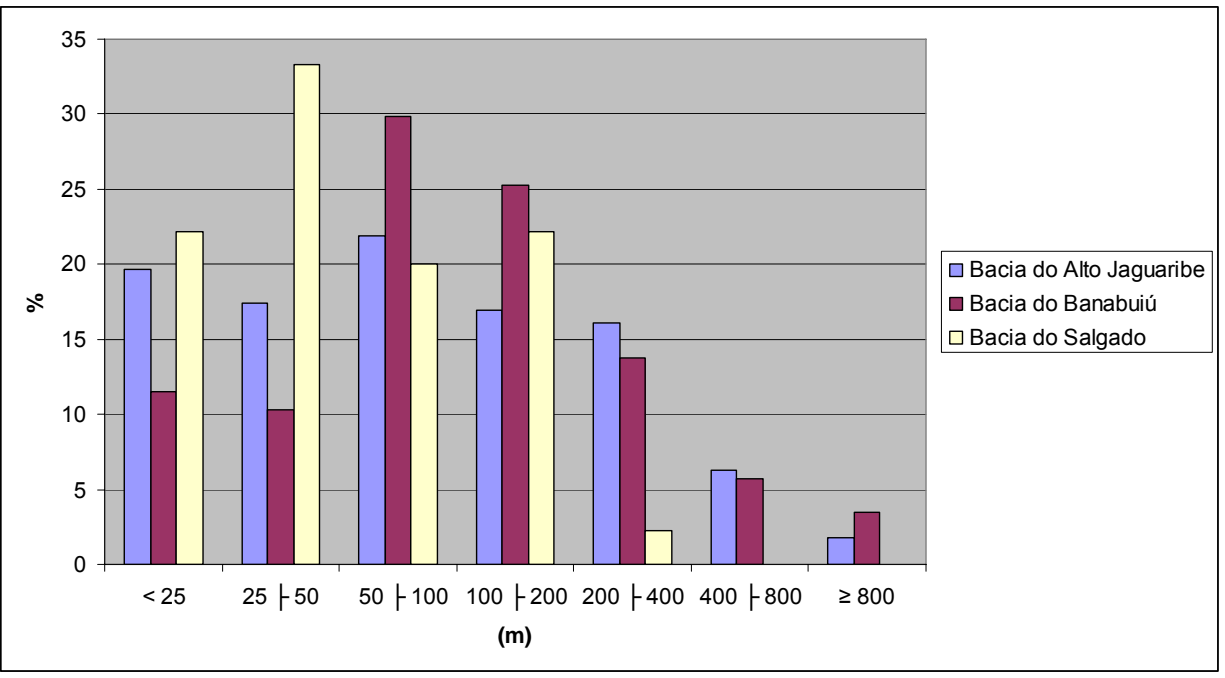

Figura 4 - Número relativo de ilhas nas bacias do Alto Jaguaribe, Banabuiú e Salgado por classe de isolamento.

Outro aspecto relevante que deve ser levado em conta, além da distância, é a natureza biofísica da área circundante (matriz) à ilha (fragmento de habitat). Um fragmento de habitat isolado por um campo agrícola, provavelmente, não exerce o mesmo efeito isolador que a água numa ilha. As paisagens insulares constituem áreas fortemente isoladas, cuja matriz cumpre fielmente sua condição de ambiente inóspito ao fluxo de espécies. No campo agrícola, os fluxos continuam a acontecer do fragmento de habitat à fonte e vice-versa, embora a uma taxa menor. Aqui, existe resistência ao fluxo, mas nada que se compare à resistência oferecida pela água. Portanto, é essa característica da matriz que confere singularidade às ilhas artificiais para investigações biogeográficas, ecológicas e, sobretudo, para aquelas voltadas para a conservação de espécies.

\section{Conclusões}

Para as condições metodológicas em que foram conduzidos os trabalhos, pode-se concluir:

- Dos 48 açudes públicos analisados, 32 (66,7\% do total) apresentaram pelo menos uma paisagem insular ou ilha, sendo 12 na bacia do Alto Jaguaribe, 11 na do Banabuiú e 9 na do Salgado.

- O total de ilhas levantadas nas três bacias hidrográficas foi 356: 224 na bacia do Alto Jaguaribe, 87 na do Banabuiú e 45 na do Salgado. 
- Os fatores que mais influenciaram a quantidade e a distribuição insular nos açudes foram a área do espelho-d'água e o relevo.

- O tamanho das ilhas variou de 0,01 a 78,64 ha. Para o extremo inferior, coube a ilha de número 13 (açude Fogareiro). Para o extremo oposto, a ilha de maior área ficou representada pela de número 2 (açude Benguê).

- A classe de área que mais acolheu ilhas foi a de área inferior a 0,5 ha, sugerindo haver uma tendência de ilhas menores serem mais abundantes e ilhas cada vez maiores serem mais raras.

- Todas as ilhas submetidas ao Shapei apresentaram forma não circular, balizadas pelos valores 1,02 e 2,95 (mais simples e mais complexa, respectivamente).

- A ilha cuja forma mais se aproximou da forma circular foi a de número 3 (açude Quincoé). A ilha de forma mais complexa foi a de número 26 (açude Trussu). A forma predominante das ilhas para todos os açudes foi aquela tendendo ao arredondamento.

- O Fract indicou que a ilha cuja forma mais se aproximou da forma circular foi a de número 2 (açude Benguê). A forma mais complexa ficou com a ilha 6 (açude Ubaldinho). Também indicou que nenhuma ilha apresentou a circularidade perfeita e, de modo geral, revelou clara predominância da forma tendendo ao arredondamento.

- A ilha mais próxima levantada foi a de número 6 (açude Muquém), com $2 \mathrm{~m}$, e a mais remota foi a de número 45 (açude Orós), com $930 \mathrm{~m}$. A maioria das ilhas (281 ou 78,9\% do total) apresentou isolamento inferior a $200 \mathrm{~m}$. Parece ser mais fácil encontrar as ilhas remotas nas cercanias das barragens dos açudes, sugerindo a possibilidade de um padrão. Portanto, o conjunto das paisagens insulares (ilhas artificiais), com suas características estruturais conhecidas, constitui espaços singulares e atrativos para o desenvolvimento de investigações biogeográficas e ecológicas centradas na conservação de espécies.

\section{PAISAGENS INSULARES DO CEARÁ: NÚMERO, DISTRIBUIÇÃO GEOGRÁFICA E CARACTERIZAÇÃO ESTRUTURAL NAS BACIAS DO ALTO JAGUARIBE, BANABUIÚ E SALGADO}

Resumo: A construção de açudes perenes no Nordeste do Brasil acionou a fragmentação da paisagem, que criou paisagens insulares ou ilhas 
artificiais. O Ceará detém inúmeras ilhas, e o presente trabalho determinou o número, a distribuição e a localização geográfica delas nas bacias do Alto Jaguaribe, do Banabuiú e do Salgado, bem como as caracterizou quanto ao tamanho, à forma e ao isolamento. Imagens dos açudes com ilhas receberam vários tratamentos, gerando-se mapas com legendas contendo espelho-d'água e ilha(s). Dos 48 açudes públicos analisados, 32 apresentaram pelo menos uma ilha. $\mathrm{O}$ número total de ilhas levantadas nas bacias hidrográficas foi 356. Fatores tais como área do espelho-d'água e relevo influenciaram a quantidade e a distribuição insular nos açudes. $\mathrm{O}$ tamanho das ilhas variou de 0,01 a 78,64 ha. Todas as ilhas apresentaram forma não circular. A ilha mais próxima ao continente distou $2 \mathrm{~m}$; a mais remota, $930 \mathrm{~m}$.

Palavras-chave: paisagem insular; ilha artificial; açude; fragmentação da paisagem.

\section{INSULAR LANDSCAPES OF CEARÁ: NUMBER, GEOGRAPHIC DISTRIBUTION AND STRUCTURAL CHARACTERIZATION IN BASINS OF ALTO JAGUARIBE, BANABUIÚ AND SALGADO RIVERS}

Abstract: The construction of perennial dams in the Northeast of Brazil brought the landscape fragmentation into action, producing insular landscapes or artificial islands. The State of Ceará has several of those islands, and the present research aimed at determining their number, distribution, and geographic localization in the basins of Alto Jaguaribe, Banabuiú and Salgado rivers, as well as characterizing them in relation to size, shape and degree of insulation. Images of dams with islands were submitted to several treatments, so that maps with legends containing water surfaces and island(s) were generated. From the 48 public dams investigated, 32 showed at least one island. The total amount of islands surveyed in the river basins was 356 . Factors such as water surface area and relief influenced the quantity and distribution of islands in dams. The size of islands varied from 0.01 to 78.64 ha. All of the islands presented a non-circular shape. The island closest to the continent was $2 \mathrm{~m}$ away from it and the remotest one was $930 \mathrm{~m}$ away from it.

Keywords: insular landscape; artificial island; dam; landscape fragmentation. 


\section{BIBLIOGRAFIA}

CAVALCANTE, A. M. B. (2008). Ilhas artificiais no semiárido: hábitats ou cárceres? Scientific American Brasil, ed. 73, p. 88-91.

GREEN, B. H.; SIMMONS, E. A.; WOLTJER, I. (1996). Landscape conservation. Some steps towards developing a new conservation dimension. A draft report of the IUCN-Cesp landscape Conservation Working Group. Ashford: Wye College.

LORD, J. M.; NORTON, D. A. (1990). Scale and the spatial concept of fragmentation. Conservation Biology, v. 4, p. 197-202.

MACARTHUR, R. H.; WILSON, E. O. (1967). The theory of island biogeography. Nova Jersey: Princeton University Press.

MCGARIGAL, K.; MARKS, B. J. (1995). Fragstats: spatial pattern analysis program for quantifying landscape structure. Portland: Dep. of Agriculture, Forest Service, Pacific Northwest Research Station.

METZGER, J. P. (1999). Estrutura da paisagem e fragmentação: análise bibliográfica. An. Acad. Bras. Ci., v. 71, p. 445-463.

. (2003). Estrutura da paisagem: o uso adequado de métricas. In: CULLEN JR., L. et al. (Ed.). Métodos de estudo em biologia da conservação e manejo da vida selvagem. Curitiba: UFPR.

RÊGO-FILHO, F. F. (2008). Paisagens insulares das bacias do Salgado, Alto Jaguaribe e Banabuiú: distribuição geográfica e caracterização estrutural. Fortaleza: Uece. Dissertação (Mestrado em Geografia).

SAUNDERS, D. A.; ARNOLD, G. W.; BURBIDGE, A. A.; HOPKINS, A. J. M. (1987). Nature conservation: the role of remnants of native vegetation. Austrália: Surrey Beatty and Son, Chipping Norton.

SECRETARIA DOS RECURSOS HÍDRICOS (SRH). Disponível em: $<$ www.srh.ce.gov.br>. Acesso em: fev. 2007.

WHITTAKER, R. J.; FERNÁNDEZ-PALACIOS, J. M. (2007). Island biogeography. Nova York: Oxford University Press. 